\title{
Antropología integral y conflictos bioéticos
}

ROBERTO NORIEGA

Resumen: Toda reflexión ética se sostiene sobre una antropología de base que subyace bajo los conceptos, los valores, los principios o las normas que aspiran a hallar los caminos de la humanización de la persona. Esto es especialmente manifiesto en cuestiones que afectan a la dignidad del ser humano en lo que dice respecto a una vida hacia la plenitud. En este trabajo se señala la urgencia de aproximarse a la persona en su integralidad, como individuo y como ciudadano, afectado por la presencia de un próximo en ocasiones vulnerable. Eso supone una conjunción con las ciencias para dar razón de los movimientos del corazón humano que se realiza en el reconocer y ser reconocido por el otro. La presencia de deficiencias antropológicas reductivas en diversos conflictos bioéticos, inevitablemente pondrá en riesgo algo tan básico como las justas actuaciones hacia las víctimas de la insignificancia y el descarte.

Palabras Clave: Conflictos bioéticos, antropología, alteridad, samaritano

Abstract: All ethical reflection is maintained on a basic anthropology that underlies concepts, values, principles or norms which aspire to find the ways of humanizing the person. This is especially evident in matters that affect the dignity of the human being when it is referred to a life towards fullness. This paper points out the urgency of approaching the person in his wholeness, as an individual and as a citizen, affected by the presence of a neighbour who is sometimes vulnerable. This suggests a conjunction with sciences to account for the movements of the human heart that occur in recognizing and being recognized by the other. The presence of reductive anthropological deficiencies in various bioethical conflicts will inevitably put at risk something as basic as the right actions towards the victims of negligence and marginalization. 
KEYWORDs: Bioethical conflicts, anthropology, otherness, Samaritan

\section{Introducción}

La preocupación de pensar los conflictos bioéticos camina junto a la reflexión del ecofeminismo y las éticas de los cuidados, y grandes propuestas de acción social (repartir el trabajo, garantizar el empleo y la renta básica), pues tienen en común los sujetos, las personas que deberían ser el centro de las instituciones que activan esas inquietudes para recorrer acertadamente el camino hacia un porvenir en el que apenas se vislumbran algunos de sus trazos todavía en brochazos grandes.

Se puede partir de dos breves textos de Agustín de Hipona para enmarcar la temática:

El primero es de las Confesiones y tiene que ver con la propia persona: «Y van los hombres a admirar los altos montes, y las ingentes olas del mar, y las anchísimas corrientes de los ríos, y el ámbito del océano, y el curso de los astros, $y$ se olvidan de sí mismos...»1.

El segundo es de la Ciudad de Dios y tiene relación con el entendimiento del individuo con los otros, cuando respeto de la diversidad de lenguas que separan al ser humano y dificultan comunicar sus sentimientos, dice que los hombres están de mejor gana "con su perro que con un hombre extraño"2.

Con ambos textos se quiere señalar la doble tarea de la antropología en su relación con los temas bioéticos.

Primero: la referida a pensar el yo, descubriendo los límites, la integración de la persona (que se presenta con su apariencia externa, tras las que se esconde un abismo, con complicada articulación), la propia aceptación, la gestación de la identidad, la asunción de las propias responsabilidades...

Segundo: la referente a pensar a los otros que participan en la tarea anterior, su importancia en una vida de imposible aislamiento, su aceptación como prójimos, y su espacio racional y vital, especialmente el de las víctimas que sufren las consecuencias de las acciones del individuo.

\footnotetext{
${ }^{1}$ Conf., X, 8, 15.

${ }^{2}$ Civ. Dei, XIX, 7.
} 
Podrían corresponderse con los interrogantes con los que terminan Albert Cortina y Miguel Ángel Serra, el texto generado tras un debate planteado en un blog en el website del periódico la Vanguardia, a respecto de las posibilidades que se abrían ante un futuro tecnológico y transhumanista. Concluían el libro ${ }^{3}$ con diez interrogantes resumidos así:

- ¿Cuáles son las condiciones específicas del ser humano que somos y cómo las podemos cultivar para evolucionar y llegar a ser lo que queremos ser como especie y como individuos particulares sin perdernos en el camino?

- ¿Cómo proceder, que procedimientos desarrollar, para responsabilizar a cada ciudadano en la propia perfección humana, incluyendo su capacidad relacional, y cómo implicarlo en el desarrollo -al menos mínimo- de unas condiciones humanas dignas para los demás en un futuro mundo sostenible y respetuoso con la naturaleza y todos los seres en ella presentes?

Es posible identificar este doble desafío en la base de varios de los 17 Objetivos del Desarrollo Sostenible de la Agenda 2030 y realimentar la pregunta por la ética de la vida, que escapando a las modas académicas cuestiona una dimensión esencial del ser humano que continúa buscándose a sí mismo en el siglo XXI.

Paralela a la base antropológica que subyace a los dilemas éticos es la advertencia de que no deja de ser una pregunta hecha a la intemperie -como los pobres que duermen en los refugios o bajo los puentes de las ciudades-, porque carece de fuerza normativa y protección que la fortalezca, frente a las divisiones casi esquizofrénicas de aquellos que la separan tantas veces en la gestión de sus acciones, privadas o públicas. No asusta esa realidad siendo que los conflictos pueden favorecer el avance de la deliberación.

Afortunadamente, hoy se captan deseos de proponer una ética de la vida atractiva y seductor $a^{4}$, con la exigencia de ser útil ${ }^{5}$, de salir del espacio

${ }^{3}$ Cfr. Albert Cortina - Miguel Ángel Serra (coords.), ¿Humanos o posthumanos? Singularidad tecnológica y mejoramiento humano (Fragmentos 33), Barcelona 2015, 479-480.

${ }^{4}$ Francisco José Alarcos Martínez, Ética para seducir. Cinco vías para hacer creíble la ética cristiana (Biblioteca Herder), Barcelona 2015.

${ }^{5}$ Cfr. Adela Cortina, ¿Para qué sirve realmente...? La ética, Paidós, Barcelona $2013^{2}$. 
teórico y alcanzar la mente y el corazón de los ciudadanos, que capte el anhelo de felicidad constitutivo del ser humano, pleno de deseos que lo edifican, lo poseen, lo modelan. Se propone pensar una ética cordial, beneficiosa, que integre todas las dimensiones de la vida, de la mano de la ejemplaridad de los que la predican para que todos estimen su importancia. Se sabe que es una empresa desafiante y peligrosa respaldada en la búsqueda de la verdad ampliada sobre el ser humano que supera los principios y las normas de acción y la reducción de los datos bioquímicos-psicológico-genéticos-neuro-hormonales.

\section{Orígenes de la pregunta por una antropología integral}

El ser humano que recibe la vida sabe o sabrá que tiene posibilidad de vivir en este mundo 'de modo humano', protegido por sus derechos y en compañía de personas que como él fueron arrojadas a la vida sin ser preguntados. Descubrirá pronto que está acompañado de modo permanente por la amenaza de «lo inhumano». Que dicha amenaza es radical, y nunca la podrá evitar por la condición vulnerable de los individuos. Jamás se encontrará totalmente a salvo, ni protegido por completo, expuesto al peligro de la limitación y de la finitud ${ }^{6}$. El cosmos se puede convertir en caos en un instante, con la inevitable perspectiva final de la muerte.

Por otro lado, los dilemas biográficos supondrán, más tarde o más temprano tomar decisiones a respeto de la vida propia o de los demás, decisiones de las que no se puede abandonar la sombra de la responsabilidad como "acto ante uno mismo, delante de alguien, por algo y según unas reglas" 7 , un acto de una conciencia que busca actuar en torno de la verdad del ser humano, de su vida y de su muerte.

Apremia el cambio constante, urgen los nuevos descubrimientos científicos y su aplicación técnica han sobrepasado las posibilidades de ficción, y están incorporándose en la práctica diaria en las decisiones que se toman en laboratorios y hospitales generando preguntas nunca realizadas y acen-

\footnotetext{
${ }^{6}$ Cfr. JoAn-Carles Mèlich, Ética de la compasión, Herder, Barcelona 2010 2 imp, 8. (Versión electrónica)

${ }^{7}$ Cfr. Julio Luis Martínez, Conciencia, discernimiento y verdad (BAC 242. Teología. Estudios y ensayos), BAC, Madrid 2019, 320.
} 
tuando dimensiones de la verdad de lo humano para las que no siempre existe respuesta ya dada porque no sirven las lógicas clásicas.

Estas tres ideas -vulnerabilidad, responsabilidad y novedad-obligan a seguir preguntando: ¿qué es lo específico del ser humano? ¿qué es la persona? Y posteriormente cuestionarse cómo tratarla, cuáles son sus derechos y obligaciones. O lo que es lo mismo, cuáles son su estatuto ontológico y ético/jurídico.

La sincera preocupación por actuar desde la verdad de la condición humana pide a la bioética una disponibilidad auténtica para buscar y estar abierta a la información que dice la realidad toda. Por lo que las ciencias son un medio indispensable de desentrañar el misterio de lo humano abierto a los mundos trascendentes, los cuales amplían los horizontes inquietos.

\subsection{La persona es un abismo de deseo en proyecto continuo}

Las preguntas anteriores ya están en cierto modo respondidas. Deben seguir respondiéndose en cada época y por cada individuo ante las dimensiones abismales que se encuentra en su interior ${ }^{8}$.

La persona es un abismo interior lleno de pliegues y grutas en las que se esconden las diversas necesidades físicas, morales, espirituales y religiosas $^{9}$ que se van exhibiendo y redactando biografías acompañadas por los con-peregrinos del camino.

Encauzar los deseos indómitos que dan forma a sus necesidades hacen visibles las propias contradicciones ${ }^{10}$ (en términos cristianos el drama del pecado), acompañantes puntuales o permanentes que conflictúan con la búsqueda de los espacios de libertad.

- Estos deseos alimentan algunos riesgos que amenazan al individuo cuando busca compulsivamente una identidad que lo distinga de los demás y lo arrastre a la esclavitud de sus propios deseos: “Aque-

8 “Abyssus abyssum invocat”. El abismo del hombre llama al abismo de Dios aplicándoselo al abismo interior de la conciencia humana. SAN Agustín, Conf., XIII, 14. 15.

${ }^{9}$ Cfr. Olegario González de Cardedal, Figuras morales frente a ídolos: Diario ABC (8 de julio del 2008) La tercera.

${ }^{10}$ JAVIER CERCAS, Elogio de la contradicción: El País Semanal (20 de octubre de 2019) 8. 
llos que permanecen esclavos de sus deseos, emociones, impulsos, temores o prejuicios, al margen de su intelecto educado, no pueden nunca llegar a ser libres"11.

- Las contradicciones y los excesos del individuo amenazan a las instituciones, por ejemplo, a la familia: "el excesivo individualismo propio de nuestra cultura favorece el debilitamiento del desarrollo y la estabilidad de las relaciones personales, afectando especialmente a los vínculos familiares" 12 .

E incluso debilitan la estructura democrática. Así se señala el desencanto político ${ }^{13}$ (especialmente entre los jóvenes) y el miedo ${ }^{14}$ como cuna de reacciones populistas de corte xenófobo que se están dando en todo el mundo.

\subsection{La responsabilidad en las sociedades plurales}

La interrogación por la persona en su totalidad parece esencial para captar la hondura de su porción de responsabilidad como sujeto de las instituciones. Recuérdense las palabras de Savater cuando afirma que la democracia "es el régimen político en el que la culpa de lo que pasa la tienen los ciudadanos" 15 olvidado con frecuencia en los tiempos electorales.

Suele ser recurrente en el dialogo sobre temas políticos plantear las responsabilidades de los candidatos electos para solucionar los problemas

\footnotetext{
${ }^{11}$ Cfr. CÉsAr Antonio Molina, Europa debe resistir: Diario El Mundo (15 de mayo del 2018)

https://www.elmundo.es/opinion/2018/05/15/5af9aa4c268e3e5a2f8b45de.html (noviembre del 2019)

${ }^{12}$ Maria Teresa López López, Hablemos de la familia: Diario ABC (5 de junio del 2015) La tercera.

${ }^{13}$ Cfr. Julio L. MArtíneZ, (Re)pensar Europa: Diario ABC (12 de diciembre de 2017) La tercera.

${ }^{14}$ Cfr. CÉsar Antonio Molina, Europa debe resistir: Diario El Mundo (15 de mayo del 2018)

https://www.elmundo.es/opinion/2018/05/15/5af9aa4c268e3e5a2f8b45de.html (noviembre del 2019)

${ }^{15}$ Cfr. Fernando Savater, Díez: Diario El País (6 de octubre del 2018)

https://elpais.com/elpais/2018/10/05/opinion/1538769854 311784.html (diciembre del 2019).
} 
de las naciones ${ }^{16}$, sin recordar las responsabilidades de los propios ciudadanos al escoger representantes con indicios de incapacidad para los diálogos que se les exigirán.

La madurez democrática adquiere rostro cuando hay conciencia y se han asumido las propias responsabilidades y se superan las parálisis del miedo, la incertidumbre de cruzar mares nunca antes navegados o cualquier tipo de atadura que bloquea la elaboración de proyectos de futuro común.

Pensar al hombre es tener en cuenta que la persona, el ciudadano, no necesita solamente que lo gobiernen, sino también que lo estimulen en la vivencia y preocupación por las temáticas sociales de las que es responsable. Es hacerle consciente de los propios deberes independientemente de los espejismos de las labores de los demás. Es hacerle partícipe activo de la realidad de la justicia y de la paz social, basada en verdades y valores que no se pueden hipotecar.

Lo cual se contrapone a la verdad que exagera las promesas de la autonomía irresponsable provocando el desacierto en el rumbo, la confusión del yo hiperconectado en fuentes de información de signos contradictorios y las inundaciones narcisistas:

El individuo consciente y autónomo soñado por la democracia ... está degenerando en un narcisista. Patológicamente concentrado sobre sí mismo, aislado e infeliz, el narcisista es víctima de una distorsión cognitiva, puesto que reinterpreta todo a la luz de sus propias necesidades psicológicas. Crea en torno a sí, en suma, un mundo psicomorfo ${ }^{17}$.

Los deseos anteriores del hombre libre hay que conjugarlos con la responsabilidad en su entorno. Se trata, por lo tanto, de pensar mejor y de modo íntegro al individuo y las formas de llegar a él, para sopesar nuevas vías de poseerse y compartirse en el siglo XXI e integrarlo en instituciones justas que generan confianza y garantizan el cuidado de las personas. Se aspira a superar esta época de la muerte del vecino por ignorado. A pensar en serio al hombre y a la mujer de modo que genere confianza en sí misma

${ }^{16}$ Cfr. JAVIER Rupérez. Esperanza para un país encogido: Diario ABC (27 de diciembre del 2019) La Tercera.

${ }^{17}$ Cfr. Giovanni Orsina, Enfermedad, democracia y populismo: Diario El Mundo (7 de setiembre de 2018) 17. 
y en el vecino para resolver los conflictos. Olegario González de Cardedal denuncia que no siempre es así.

Una sociedad que comienza a pensar que su vecino, amigo o compañero de trabajo, pueden delatarle es una sociedad donde está siendo cortada la raíz de la libertad. La confianza colectiva en que son el derecho, la justicia y la libertad los que priman frente a la impunidad, la delación, la envidia o la sospecha son condición de la paz verdadera, tanto de la personal como de la social ${ }^{18}$.

\subsection{La provocación de las víctimas}

Al preguntarse por la verdad integral del ser humano no se puede olvidar la perspectiva de las víctimas. Dicha verdad recuerda que a veces -desde posiciones sociales más o menos cómodas-, no se percibe que se es victimario, no en el sentido fuerte de ser homicidas, sino en el sentido más débil de ser insensibles al dolor y a las necesidades, de hacerse irresponsable de las heridas de los otros, tal vez provocadas inconscientemente. Lo que en términos teológicos se denomina pecado estructural y que Innerarity presenta así:

Los principales problemas a los que se enfrenta hoy la humanidad tienen el carácter de problemas planteados por un sistema interdependiente y concatenado ante los cuales son ciegos sus componentes individuales: insostenibilidad, riesgos financieros y, en general, aquellos que están provocados por una larga cadena de comportamientos individuales que pueden no ser en sí mismos malos, pero sí lo es su desordenada agregación ${ }^{19}$.

La parábola del samaritano del Evangelio (Lc 10,29-37) pone sobre la mesa precisamente esta realidad de ciudadanos cuyas primeras necesidades no pasan por tener en cuenta a los que se encuentran a la orilla del camino. Leída de inicio con ojos de fe, ha sufrido un desplazamiento en su lectura complementaria hacia la razón universal no excluyente.

${ }^{18}$ Cfr. Olegario GonzÁlez de Cardedal, Alegría y coraje: Diario ABC (7 de octubre de 2018) La Tercera.

${ }^{19}$ DANIEL INNERARITy, Sobrevivir a los malos gobernantes: Diario El País (4 de enero del 2017)

http://elpais.com/elpais/2016/12/28/opinion/1482948155_120317.html (enero del 2017) 
Una reflexión que tenga en el centro el ser humano incomodará incluyendo toda persona que sufre las consecuencias de la injusticia de las sociedades del bienestar. Mientras existan colectivos excluidos al margen de los procesos decisorios por falta de representación no serán sociedades del todo y para todos humanas.

Los otros, la preocupación por el otro, por las personas especialmente las más vulnerables ${ }^{20}$, aquellas de las que se podría dudar de su no ser por motivos diversos son el termómetro que marca la temperatura de un cuerpo social sano en el que todos son "homo mendicans".

En ese cuestionamiento es bienvenida la incorporación de las generaciones futuras a tener en cuenta para valorar las consecuencias de las decisiones actuales en una dinámica global. Se recupera así la intuición inicial de uno de los padres de la bioética moderna que la comprendía como una ciencia nueva para tender puentes hacia el futuro definiéndola como "una nueva disciplina que combina el conocimiento biológico con un conocimiento de sistema de valores humanos" 21 .

\subsection{La urgencia de los cuestionamientos actuales}

Las espectaculares novedades tecnológicas y sus posibilidades hacen estremecer lo que el sujeto humano es y será, cómo se le concibe y cómo se le imagina. Se plantean dudas, se buscan definiciones y límites como nunca se hizo $^{22}$. Las formas provocativas y desafiantes dificultan precisar lo que responde a un mero desprecio o a una confianza ilimitada en las posibilidades de la razón que imagina una mejora ética ${ }^{23}$ en un progreso que no será solamente tecnológico, sino también intelectual, ético, político y religioso.

Las novedades conjuntadas con la velocidad tornan urgente identificar lo específicamente humano ${ }^{24}$ y sus límites. En el sondear nuevos modos

${ }^{20}$ Cfr. Teología desde las víctimas (Tirant humanidades), Valencia 2017.

${ }^{21}$ VAn Rensselaer Potter, Bioethics. Bridge to the future (Biological science), Englewood cliffs (NJ) 1971, vii.

${ }^{22}$ CRISPR... ¿debemos poner límites a la edición genética? (Cuadernos de la Fundació Víctor Grífols i Lucas 45), Barcelona 2017.

${ }^{23}$ Cfr. Julian SAVulescu, ¿Decisiones peligrosas? Una bioética desafiante (Filosofía y ensayo), Madrid 2012.

${ }^{24}$ CARlos Beorlegui, Humanos. Entre lo prehumano y lo pos- o transhumano (Ciencia y religión 14), Sal Terrae/Comillas, Bilbao 2018, 526. 
de expansión de lo humano sin dejar de serlo se renueva el debate entre la naturaleza y la condición humana, entre la genética y la biología. La neurociencia ha suscitado nuevas cuestiones sobre el papel del cerebro y el funcionamiento de la mente de tal modo que hay que repensar el espacio de la libertad clave para sostener la moralidad del sujeto, la relación con lo trascendente, con lo metafísico y lo simbólico.

Resulta especialmente atractiva por cercana la pregunta por el ser humano en lo que dice respecto a su cuerpo en la integración de la persona. No son pocas las voces que claman contra la creciente comercialización del cuerpo y sus partes separándolo de la unidad personal. Escribe Casado:

¿cómo es posible que se sigan declarando válidos los principios de justicia global y respeto a los derechos humanos reconocidos y, no obstante, cada vez en mayor medida, se acepte la comercialización del cuerpo humano, de sus partes y de sus componentes? ${ }^{25}$.

Y es que las técnicas abalanzadas sobre el soporte físico han generado un 'mercado del cuerpo', que en tanto que materia orgánica considerado por entero o descompuesto en partes (genes, células, órganos, tejidos...) puede ser considerado como una nueva medida del ser humano al ocupar todos los campos de la economía como moneda de cambio, materia prima, fuerza de trabajo, objeto de experimentación y de consumición. La profundidad de la cuestión es tal que Lafontaine cree que el cuerpo como mercancía es la base de lo que ella denomina la sociedad post-mortal ${ }^{26}$.

Para llegar a ese punto, se ha dado un proceso de objetivación, e instrumentalización anticipo de la mercantilización, que tiene que ver con el apartado anterior de las víctimas de la sociedad del bienestar, pues evidentemente las personas que están en la base del mercado, los que menos recursos tienen, los más vulnerables, los menos defendidos, los que no tienen voz ni rostro, los no representados, tienen la mayoría de las probabilidades de entrar en la espiral destructora del mercado. Los que se favorecen de dichos procesos de mercantilización son los países de la

${ }^{25}$ MARÍA CASAdo, (coord.), De la solidaridad al mercado. El cuerpo humano y el comercio biotecnológico (Bioética), EUB-Fontamara, e-book, presentación.

${ }^{26}$ Cfr. CÉline LAFOnTAINE, Le corps-marché. La marchandisation de la vie humaine à l'ère de la bioéconomie, Éditions du Seuil, Paris 2014. Edición digital, Introducción. 
Unión europea y de Norteamérica, grandes beneficiados, por ejemplo, de los trasplantes renales.

Los perfiles de tales encrucijadas son sublimes hasta el punto de afectar al discurso altruista enhebrándolo en la aguja del interés mercantilista que minusvalora a la persona en un reduccionismo corporal. Algo de ello denunció Hans Jonas tras la decisión de la comisión de Harvard de tomar la muerte encefálica como criterio para definir la muerte que permitiese el uso de órganos para trasplante.

La certeza moral práctica en la toma de decisiones, los principios éticos para dirimir tales cuestiones comprometen una acertada comprensión de la unidad personal. La falta de reflexión en este sentido de integrar la persona entera parece ser una puerta abierta a las desigualdades de clase, raza y de género entre otros.

\section{Lo que humaniza en el conflicto}

Es moneda común apuntar que los conflictos son las fronteras en las que la ética ensancha sus horizontes:

[...] la ética emerge en una situación en la que uno no puede encontrar a priori una respuesta a la pregunta ¿qué debo hacer? [...] Por eso, si la ética tiene sentido, es porque frente a una situación nos quedamos perplejos y nos damos cuenta de que las normas, el marco normativo en el que hemos sido educados, o en el que habitamos -nuestra gramática-, fracasa radicalmente ${ }^{27}$.

Su novedad provoca que la gramática con la que se deben escribir las normas esté en riesgo de fuera de juego, o al menos sea cuestionada en sus raíces. Hay suficiente consenso en los Derechos Humanos, no tanto en medio de las dificultades de su aplicación y salvaguarda.

Aquí es donde tiene sentido revisitar la pregunta por lo que constituye lo humano rescatando una antropología -un renovado y auténtico humanismo- que cimiente los valores.

${ }^{27}$ JoAn-CARles MÈlich, Ética de la compasión, Herder, Barcelona $20102^{\mathrm{a}}$ imp, 8990. 
El dilema no es ideológico, sino profundamente humano. Debemos construir un renovado humanismo de base espiritual sustentado en una cosmovisión que no pretenda desautorizar la ciencia, sino complementarla y enriquecerla, ya que el hombre está hecho de alma y de razón, de espíritu y de materia. No se trata de matar al enfermo, sino de curarlo, pues en él la bestia puede ser domada y convertida ${ }^{28}$.

Se tratará de señalar dicho humanismo a partir de los datos que las ciencias ofrecen sobre la persona, acerca del prójimo, el deseo y la razón.

\subsection{Conjunción de todas las ciencias}

Acudir a las ciencias es insoslayable criterio epistemológico de la reflexión ética ${ }^{29}$, para captar y comprender la entidad del hombre, aprehendida en su complejidad, antes de procurar los cursos dignos de acción.

Un apunte primero para acercarse a lo que es el ser humano y resolver los conflictos bioéticos será de orden metodológico en el sentido de incorporar articuladamente los conocimientos de todas las ciencias provocadoras del dilema de lo humano tras poner en entredicho la comprensión de su imagen, humus en el que se enraíza su definición.

Baste recordar que la genética reduce las diferencias con los simios superiores a una mínima porción de información. O la neurología que cuestiona la experiencia de la libertad sembrando dudas acerca de una condición 'esencial' del sujeto prisionero de las apreciaciones ilusorias de su cerebro. O las tecnologías bioinformáticas que ofrecen posibilidades de mejora y adquisición de cualidades ajenas al cuerpo humano; ¿se le podrá denominar así en unas decenas de años?

Si se compara la definición clásica de la persona-naturae rationalis individua substantia ${ }^{30}$ - con la siguiente afirmación se pone rostro a la cuestión:

${ }^{28}$ Pérez Sánchez Ferré, en: Alberto Cortina - Miquel-Àngel Serra, ¿Humanos o posthumanos? Singularidad tecnológica y mejoramiento humano (Fragmentos 33) Barcelona 2015, 371-372.

${ }^{29}$ Cfr. Julio Luis Martínez, Conciencia, discernimiento y verdad (BAC 242. Teología. Estudios y ensayos), BAC, Madrid 2019, 324-325; Pontificio Consejo "Justicia Y PAZ", Compendio de la Doctrina social de la Iglesia, Biblioteca de Autores Cristianos (BAC) y Editorial Planeta, Madrid 2005, 76-78.

${ }^{30}$ BoECIO, De persona et duabus naturis contra Eutychen et Nestorium, cap. 3; PL 64, 1343. 
[las personas] Somos complejos mecanismos conformados y movidos por genes, reconfigurados después por complejos mecanismos epigenéticos, así como por intrincados entramados neuronales, que rigen el desarrollo y las metas de nuestra conformación morfológica, al igual que las diversas estructuras mentales y comportamentales que marcan, de forma más o menos rígida, nuestras interacciones con el entorno natural y con el resto de los integrantes de nuestra especie ${ }^{31}$.

Ante la dificultad de definir qué es la persona desde las ciencias empíricas y para salir del paso -desde niveles jurídicos o cibernéticos- se han acuñado referencias adjetivadas a otros tipos de persona. Se ha hablado de la persona no humana (referida a los simios superiores), persona digital referida a los ciborgs y humanoides ${ }^{32}$; se ha sugerido conceder personalidad jurídica a los robots ${ }^{33}$.

Asimismo, una limitación de las ciencias teóricas es utilizar un prisma en el que parece predominar el naturalismo reduccionista ${ }^{34}$ que estruja la identidad de lo humano con la prensa de los meros datos científicos. Dos de las consecuencias a las que conducen dicha opción son no valorar con suficiencia las cosmovisiones y presupuestos que sostienen dicho reduccionismo, y extraer conclusiones contradictorias a partir de presupuestos que no se corresponden con su ámbito.

En esa dinámica se encuentran autores que consideran la filosofía o la espiritualidad como restos de una mentalidad mítico/religiosa superada $^{35}$ sosteniendo hipótesis extrañas y discordantes con las evidencias científicas que ellos sostienen, o recargando con exclusividad su perspectiva científica en relación con las demás ciencias ${ }^{36}$.

${ }^{31}$ Carlos Beorlegui, Humanos. Entre lo prehumano y lo pos- o transhumano (Ciencia y religión 14), Sal Terrae/Comillas, Bilbao 2018, 17-18.

${ }^{32}$ Seres que no son autónomos, sino autómatas programados por otros. AdELA CoRTINA, Ética digital: Diario El País (7 de diciembre de 2018) 11.

${ }^{33}$ Parlamento Europeo, Resolución del 16/2/2017, 59 f

${ }^{34}$ Carlos Beorlegui, Humanos. Entre lo prehumano y lo pos- o transhumano (Ciencia y religión 14), Sal Terrae/Comillas, Bilbao 2018, 11-13.

${ }^{35}$ Cfr. CARlos Martínez A. - JAVIER LóPez FaCAL, El embrión y sus circunstancias: Diario El País (9 de noviembre de 2010) 33 (La cuarta página)

${ }^{36}$ Somos máquinas complejas a las que se puede hacer inmortales con el simple recambio de piezas/órganos. Cfr. ANA CARBAJOsA, "Pensar que podemos vivir 1.000 años es 
Por supuesto que las ciencias humanas son presionadas hacia su renovación para incorporar los datos técnicos, de tal modo que hasta la misma teología está haciendo ese ejercicio ${ }^{37}$ llegando a la conclusión de que "no hay una definición unívoca de la esencia del hombre, sino ante todo una consideración articulada de su ser como sujeto de múltiples relaciones" 38 .

Así que para conocer la verdad del ser humano en su mayor amplitud será necesaria una sinergia de fuerzas, que superen la parcialización en compartimentos estancos de la esencia de lo humano.

No es una investigación que deba responder solamente a criterios de los técnicos, ni de ingenieros, ni de matemáticos a la búsqueda del algoritmo perfecto, pero tampoco se puede prescindir de sus estudios obligando así a desarrollar estrategias y ampliar los espacios públicos de participación. Lo que humaniza tiene que ser descubierto en una suma de fuerzas y ciencias. Las ciencias como pregunta, de las ciencias la respuesta.

\subsection{La pregunta por el sujeto humano y su especificidad}

Aplicar el foco de la ciencia para iluminar lo que se entiende por naturaleza o condición humana en constante evolución, significa identificar criterios indicadores del progreso o alejamiento de dicho ideal.

Se ha hecho referencia al término 'persona no humana', referido como se sabe a un simio superior para hacer uso de un recurso jurídico que posibilitaba su excarcelación de un zoológico y su posterior liberación en un ambiente natural.

una cifra conservadora". Entrevista a Aubrey de Grey, Gerontólogo: Diario El País (20/10/2016)

http://elpais.com/elpais/2016/10/13/ciencia/1476353983 661713.html (diciembre del 2019)

${ }^{37}$ Cfr. Pontificia Accademia Biblica, Che cosa è l'uomo. Un itinerario di antropologia biblica, Libreria Editrice Vaticana, Roma 2019. Es un documento que repiensa la lectura del texto bíblico hecha hasta ahora a raíz de los descubrimientos de las ciencias experimentales.

${ }^{38}$ Pietro Bovati, Che cosa é l'uomo? Il Documento della Pontificia Commisione Bíblica, Vatican News, 9 de enero del 2020.

https:/www.vaticannews.va/it/vaticano/news/2020-01/cosa-uomo-documento-pontificia-commissione-biblica.html (febrero del 2020) 
La argumentación empleada fue la siguiente; "Sandra" es una persona no humana "ya que mantiene lazos afectivos, razona, siente, se frustra con el encierro, toma decisiones, posee autoconciencia y percepción del tiempo, llora las pérdidas, aprende, se comunica y es capaz de transmitir lo aprendido" 39 .

Con este ejemplo se quiere traer a la palestra la dificultad de debatir acerca de las cualidades que identifican lo humano y su posterior definición. Cuestión planteada de diversos modos y en diversas ocasiones. Ya se ha recordado a Boecio en el siglo V-VI. Son clásicos Ricardo de San Víctor en el siglo XII (La persona es un existente por sí mismo con cierto modo singular de existencia racional), y Duns Scoto en los inicios de la modernidad (Persona es incomunicabilidad que posee existencia en una naturaleza individual).

La individualidad es acentuada actualmente por los teóricos del transhumanismo en su apuesta por la singularidad, y Beorlegui siguiendo su estela amplía su perspectiva y entiende que a la hora de identificar aquello que es propio y singular del ser humano, tal vez no debamos orientarnos hacia una característica específica:

Nuestra singularidad no la vamos a encontrar en una sola de nuestras características, sino en el conjunto de todas ellas, en la medida en que dicha totalidad no puede constituir el objetivo de las ciencias, sino una interpretación provisional de la filosofía ${ }^{40}$.

Los serios interrogantes planteados afectan al aprecio por la grandeza de lo humano con enormes consecuencias. En ese sentido apostar a la baja en la concepción de lo humano es renunciar a su dignidad, siendo los más necesitados, los vulnerables, aquellos individuos cuyos perfiles de vida no encajan fácilmente con su reconocimiento como personas, las víctimas de estos desenfoques antropológicos.

39 Juan Ignacio Irigaray, Conceden el hábeas corpus a Sandra, una orangután del zoo de Buenos Aires: Diario El Mundo (21/12/2014)

https://www.elmundo.es/internacional/2014/12/21/5496e8c622601dcd148b4571.html (diciembre del 2019)

${ }^{40}$ Carlos Beorlegui, Humanos. Entre lo prehumano y lo pos- o transhumano (Ciencia y religión 14), Sal Terrae/Comillas, Bilbao 2018, 21. 
Solamente una idea elevada de lo que el hombre es y representa y la admisión de que, aunque haya surgido de los avatares de la evolución, está por encima de ella, permiten continuar hablado de la dignidad humana. Y solo desde estas premisas antropológicas es lógico y fundamentado rechazar ciertas medias eugenésicas contrarias a esa dignidad ${ }^{41}$.

En lo específico de individuo humano se encuentra su ser único, soporte de su vida social y de su apertura a los otros, con capacidad para la Trascendencia que completa su totalidad. La índole social le habilita para formar un nosotros, abierto al todos universal de una sola familia humana, que garantiza su plenitud ${ }^{42}$ exigiendo correspondientemente la atención del grupo hacia el individuo. Afirmar este dinamismo no significa divinizar la sociedad ni deformar al individuo, como ha sucedido en el seno de algunas tradiciones que no han sabido transcribir correctamente esta tendencia ${ }^{43}$. Unas han sobrevalorado la autonomía y la libertad aislándolas de la pregunta por la verdad global -lo cual puede llegar a destruir a la propia persona ${ }^{44}$, , otras han caído en el exceso de celo comunitario frente al sujeto particular.

Así pues, los criterios que se usen deben corregir esos desenfoques para atender las dependencias y las fragilidades con las que debe lidiar la bioética con justicia junto al individuo y su entorno, la persona y sus instituciones. Lo que humaniza tiene que ver con la globalidad de la persona humana, integrando no tanto una condición que lo distingue absolutamente y lo identifica sino el conjunto de sus cualidades.

\subsection{La incorporación del otro al ámbito vital propio}

Vale la pena detenerse a sopesar los esfuerzos de afiliar al otro en el horizonte del ámbito vital como prójimo. El sí mismo es imposible sin los otros.

${ }^{41}$ Marceliano Arranz Rodrigo, La manipulación eugenésica de la especie humana (II): Religión y Cultura 30 (1984) 481.

42 "El hombre, única criatura terrestre a la que Dios ha amado por sí mismo, no puede encontrar su propia plenitud si no es en la entrega sincera de sí mismo a los demás". GS., 24.

${ }^{43}$ Cfr. Julio Luis Martínez, Conciencia, discernimiento y verdad (BAC 242. Teología. Estudios y ensayos), Madrid 2019, 45-48.

${ }^{44}$ Ana María Marcos Del Cano, Eutanasia ¿de qué se trata?: Diario El Mundo (sábado 6 de abril de 2019) 33 . 
Algunos análisis constatan que el individualismo ${ }^{45}$ y la autonomía como categoría máxima de la libertad personal, ha deslucido la imagen del otro en el horizonte del ciudadano actual, en base a una concepción antropológica anidada a unas condiciones de racionalidad específicas. Así se puede comprender que un autor como Peter Singer tomando la intuición de Locke ${ }^{46}$. defina la persona como "un ser pensante, inteligente, que tiene razón y capacidad de reflexión, y que puede considerarse a sí mismo como sí mismo, el mismo ser pensante, en diferentes momentos y lugares"47.

La expresión de la libertad desarrollada con la clave de la autonomía ha sido un gran avance que abre muchas posibilidades de comprensión de las actividades y manifestaciones que puede realizar el espíritu humano. Pero una tal comprensión de la libertad puede no captar todas las raíces relacionales y los frutos de sus interacciones.

Para compensar los excesos de la reflexión individualizante se encuentran investigaciones que suben a la balanza de la igualdad las dimensiones sociales y culturales elementos fundamentales en el proceso de humanización ${ }^{48}$. La no atención al desarrollo de dichas dimensiones en beneficio del individuo aislado no hace justicia a la esencia de la persona ${ }^{49}$.

Apreciar esas dimensiones culturales solo desde el deseo o la voluntad de cada individuo, identificando sus impulsos primarios interiores sin

${ }^{45}$ González de Cardedal, presenta la absolutización o idolatría de la libertad, junto con el individualismo, la arbitrariedad, la imposición de la decisión particular, la anarquía la represión de la vida del prójimo desde la afirmación incondicional de la propia..., como las patologías que afectan a la relación de la libertad con la verdad. Cfr. OLEGARIO GoNZÁlez de CARdedAl, Dios en la ciudad. Ciudadanía y cristianía, Sígueme, Salamanca 2013, 187.

46 “...debemos ahora considerar qué significa persona. Pienso que esta es un ser pensante e inteligente provista de razón y de reflexión, y que puede considerarse a sí mismo como una misma cosa pensante en diferentes tiempos y lugares; lo que tan solo hace porque tiene conciencia, porque es algo inseparable del pensamiento, y que para mí le es esencial, pues es imposible que uno perciba sin percibir lo que hace". JOHN LOCKE, Ensayo sobre el entendimiento humano, Nacional, Madrid 1980, 492-493.

${ }^{47}$ Peter Singer, Ética práctica, cap. IV. Edición digital.

${ }^{48}$ Cfr. CARlos Beorlegui, Humanos. Entre lo prehumano y lo pos- o transhumano (Ciencia y religión 14), Sal Terrae/Comillas, Bilbao 2018, 221-301.

${ }^{49}$ En sus múltiples dimensiones. Cfr. Pontificio Consejo "Justicia Y PAZ”, Compendio de la Doctrina social de la Iglesia, Biblioteca de Autores Cristianos (BAC) y Editorial Planeta, Madrid 2005, 124-151. 
incorporar la reflexión sobre esos impulsos de cara a su validación en la sociedad da como resultado una pérdida de sentido comunitario y trascendente que acentúa las deficiencias de alteridad hacia los otros.

Resolver los desajustes en el totum relacional del ser humano con distintas plataformas de expresión ha sido, es, y probablemente será una de las mayores preocupaciones de las deliberaciones teóricas y de las luchas prácticas del individuo. Lo que humaniza pasa por el espacio del otro, del vecino, del ciudadano que de algún modo tiene que ver conmigo, entra en mi mundo, me afecta. Con su saludo, con su sonrisa, con su brazo extendido dando o pidiendo ayuda, el otro forma parte de mi espacio. Este descubrimiento en ocasiones puede plantearse de modo dramático frente a las debilidades de las personas que llevan a compasión ${ }^{50}$.

\subsection{Una antropología que incorpora el deseo}

El humano es un ser que desea "amar y ser amado". Es estructuralmente constituido por el deseo, por múltiples deseos. Prima el deseo de ser (deseo ontológico dirá Torralba), sobre el deseo de tener; el deseo como estructura de lo humano, sobre el deseo como contenido de dicha estructura. El deseo afecta al sujeto individual y a las personas circundantes incluidas -directa o indirectamente- en los apelos de su voluntad.

Son cada vez más frecuente los llamados a reeducar el deseo (en términos del papa Francisco, apostar por otro estilo de vida, conversión ecológica $\left.{ }^{51}\right)$. Descentrar la voluntad de bien-estar y bien-tener y enfocarla hacia el bien ser $(G S ., 35)$ en circunstancias vitales plenas de incertidumbre, aceleración, inmediatismo, etc.... Son voces que invitan a reorientar la voluntad de tal modo que se asuma otra reflexión que identifique la responsabilidad para alcanzar la madurez como persona y tomar decisiones como ciudadano adulto.

En cuanto elemento de la voluntad articulado desde la conciencia, con otros elementos, el deseo influye en la capacidad de elección, entra de lleno en las decisiones morales y su sostenimiento, en la aproximación y colaboración con la sociedad: "Somos responsables de nuestros senti-

${ }^{50}$ JoAn-CARles Mèlich, Ética de la compasión, Herder, Barcelona $20102^{\mathrm{a}} \mathrm{imp}$.

${ }^{51}$ PAPA Francisco, Carta encíclica Laudato Si' sobre el cuidado de la casa común, Roma, 24 de mayo del 2015, 203-208, 216-221. 
mientos porque somos responsables de cultivar o rechazar las ideas que alientan esos sentimientos y sus consecuencias" 52 .

En la co-implicación ciudadano/sociedad los deseos se incorporan a las bases culturales en forma de actitudes, principios y normas de las personas y las instituciones. Se reciben y alimentan en ambientes familiares o sociales transmitidos desde generaciones, contagiados por personas ejemplares, impuestos por la mayoría o por presiones sociales y dogmáticas del grupo dominante, o adquiridos por engaño o autoengaño.

Como la relación del ámbito privado con el ámbito público puede ser escenario de conflictos a modo de placas tectónicas que pueden sobreponerse y ocultarse unas sobre otras provocando terremotos. Se deberá medir su papel en la solución de tales conflictos "por el grado de justicia de la causa política que impulsan, por la singularidad del momento y circunstancia a los que se apliquen" $" 53$.

Se quiere afirmar entonces que algunas estimativas de la actualidad antropológica con trasfondo bioético insinúan la exigencia de equilibrar la voluntad de autonomía incorporando la presencia del prójimo, una autonomía relacional.

La comprensión de la libertad compartida con el otro -criterio que más dignifica al ser humano- ayuda a gestionar los anhelos de plenitud hallando pistas de acción que sobrepasen la coerción del Código Penal al sancionar el delito de omisión del deber de socorro. Es un empeño por reeducar la voluntad corrigiendo los placeres de la sologamia y la autorreferencialidad que llevan al extremo las actitudes de las personas insolidarias y egoístas de la ya referida parábola del samaritano ${ }^{54}$.

Incluir al otro en la orientación y expresión de los deseos propios muestra la dimensión ontológica existencial (me realizo con los otros) y al mismo tiempo utilitarista como vías para un mayor estímulo de la voluntad.

Lo que se traduce en las preguntas fundamentales ¿quién es mi prójimo? ¿cómo tengo que interactuar con él y qué respeto me me-

${ }^{52}$ Aurelio Arteta, Los sentimientos son cuestionables: Diario El País (19 de octubre del 2017) 15.

${ }^{53}$ Aurelio Arteta, Los sentimientos son cuestionables: Diario El País (19 de octubre del 2017) 15.

${ }^{54}$ Cfr. Adela Cortina, Aporofobia, el rechazo al pobre. Un desafio para la democracia (Paidós. Estado y sociedad), Barcelona 2017. 
rece? ¿qué gano con ello y cuál es mi beneficio? Preguntas que han existido siempre en la historia de la humanidad alimentadas desde el ámbito religioso, que continúa siendo un espacio privilegiado de creación de humanización al recordar constantemente dichas cuestiones y canalizar sus respuestas de tal modo que pueden ser incluidas en el ámbito cultural.

La respuesta humanizante a estas preguntas -adquiridas por el ciudadano y canalizadas por las instituciones- busca razones para agilizar el paso de la reflexión a la praxis. Marina lo expresa así:

Se trata de pasar del determinismo del deseo al determinismo del proyecto, mediante el cual el deseo se vence a sí mismo. La gran función de la inteligencia no es alcanzar fines, sino inventar fines y, mediante ellos, encelar el deseo ${ }^{55}$.

Así pues, lo que humaniza pasa por redefinir la voluntad como algo esencial alimentando tres anhelos fundamentales como son deseo de bienestar personal, el deseo de relacionarse socialmente, formar parte de un grupo y ser aceptado y el deseo de ampliar las posibilidades de acción. Necesita del crecimiento de todas las dimensiones ${ }^{56}$ : la sensibilidad, la inteligencia y la afectividad. No es una tarea puntual sino un proceso sostenido y acompañado con un elemento básico en la virtud humana: el autocontrol razonable.

\subsection{La razón cordial}

Para reconocer al otro, introducirlo como prójimo en el campo de los desvelos personales y buscar su lugar en la vida de cada ciudadano no es suficiente la labor de la razón formal.

Cuando Adela Cortina elabora la fundación de la ética mínima apoyándose en la ética discursiva de Apel y Habermas, entiende que las normas morales no surgen como exigencia de establecer contratos con los otros ciudadanos, sino del reconocerlos como individuos capaces de dialogar lógicamente y expresar sus intereses. Ante esto, la razón es suficiente

\footnotetext{
${ }^{55}$ José Antonio MARINA, Las arquitecturas del deseo. Una investigación sobre los placeres del espíritu (Argumento), Anagrama, Barcelona 2007.

${ }^{56}$ Cfr. Julio Luis Martínez, Conciencia, discernimiento y verdad (BAC 242. Teología. Estudios y ensayos), Madrid 2019, 168.
} 
para identificar las normas del diálogo, pero se queda corta de miras si no conecta con los intereses del corazón humano. Su postura frente al diferente, salvo que se abra a la razón cordial, a la razón que gestiona las emociones que el otro que aparece enfrente provoca, no alcanzará su objetivo.

Si las razones del corazón no complementan la razón lógica, si el debate bioético permanece solamente en los criterios racionales sin abrir paso a la gestión de lo irracional, lo afectivo, no se alcanzará a captar los desafíos éticos que provocan los demás.

Se buscan candidatos para hacer una reflexión que equilibre lo emocional con lo racional para completar una razón humanista que conjure el riesgo de reducirse a gestionar de modo utilitario -minimizando las consecuencias- las acciones; que no polaricen la inteligencia humana entre el conocimiento y el sentimiento; que incorpore la razón sensible ${ }^{57}$ al debate sobre la moralidad para abrir las puertas a una argumentación más depurada y establecer vínculos más allá de los derechos que los ordenamientos legales garantizan. Uno de los errores en la gestión de las residencias de ancianos durante la pandemia del Covid-19 ha sucedido precisamente en esta cuestión.

En este sentido, es muy posible que con motivo de los proyectos actualmente en marcha para mapear y conocer el funcionamiento del cerebro provean de unos excelentes materiales de reflexión y levanten cuestionamientos novedosos que estimulen esta labor.

En términos agustinianos la razón cordial que fomenta el ordo amoris, es tan importante como la razón instrumental que genera el ordo rationis. "Cada una responde al doble orden de la objetividad real y de la existencia personal" ${ }^{58}$. Es algo más que la razón instrumental y dominadora. Es aglutinar una razón "compadeciente y solidaria".

Como ya se ha indicado, hay indicios fuertes de que la persona se ha hecho esclava de su egoísmo al comprenderse primariamente en clave de autonomía excluyente, y una razón cordial abierta, es uno de los caminos para regatear el riesgo de "autismo de plenitud" (el que se busca se perderá) provocado por la espiral antropológica que gira y se va encerrando estranguladoramente sobre un sí mismo nosogámico. Identifíquese en el

${ }^{57}$ Cfr. Michel Maffesoli, Elogio da Razão Sensível, Vozes, Petrópolis, RJ, 1998.

${ }^{58}$ Cfr. Olegario González de CARdedal, Alegría y coraje: Diario ABC (7 de octubre de 2018) La Tercera. 
logo del like, del I love me, paradigma de una antropología de auto esclavitud.

Hay que revisar dicha espiral destructora e insolidaria -ofreciendo instrumentos de huida- $\mathrm{y}$ abrirla razonable pero no ingenuamente hacia los demás que, desde la incomodidad de sus diferencias, enriquecen y acompañan la propia realización. Parece que atender a esa razón cordial es camino apropiado para acceder al ciudadano postmoderno, aproximarse a la comprensión de su jerarquía de valores y situarle frente a los múltiples conflictos y demás situaciones que obnubilan el aprecio de la persona.

\section{Aplicaciones en los conflictos bioéticos}

Después de haber dedicado los dos primeros ítems a la importancia de la pregunta por la antropología y a ofrecer unos elementos a incorporar en la respuesta es el momento de aplicarlos a los conflictos bioéticos.

Siendo la bioética una ciencia que está pidiendo especialización por la amplitud de los temas se tratará de unificar la mirada para evitar la distracción que pueda impedir esa unificación a la hora de valorar la realidad y contactar con el método bioético y la toma de decisiones. Hay que apuntar tanto hacia las personas que piensan la ética de la vida, cuando a las bases ciudadanas alcanzadas por los debates bioéticos en los que suelen ser 'olvidadas'.

\subsection{En la gestión de las políticas sobre la vida}

Un primer campo para pensar los conflictos bioéticos de máximos es en las políticas generadoras de legislaciones ajustadas a cada nivel: clínico, de investigación o ecológico.

En este nivel de reflexión es necesario sobreponerse a las ideologías exclusivistas para recrear la dignidad de la persona y de la vida ${ }^{59}$. Una buena política necesita una amplia concepción del ser humano para acer-

${ }^{59}$ Cfr. Ignacio SÁnchez CÁMARA, La rehumanización de Europa: Diario ABC (21 de octubre del 2019) La tercera. 
tar en sus planteamientos y aquí es donde surge el primer conflicto bioético, por la intervención de metodologías y estrategias de aproximación diversas. Lo apunta Calleja:

La consideración interdisciplinar y la entrada transversal por la diversidad de planos de la vida, sólo puede sostenerse en un paradigma cognitivo que reconozca la diversidad en lo real, a la vez que su unidad; y, en consecuencia, un paradigma que apele a la interdisciplinaridad de todos los saberes y a la transversalidad específica de la moral, como referencia siempre presente, para reconocer la huella indeleble de la autonomía humana, y el valor ético de cada empeño social ${ }^{60}$.

Continúa el conflicto en relación con los sujetos protagonistas. No hay debate en propiedad privilegiada -según solicitan voces autorizadas ${ }^{61}$ reducido a las élites científicas, éticas, jurídicas. Se aspira a incorporar de diversas maneras posibles a las bases sociales para adjudicar las responsabilidades a los colectivos correspondientes.

Parece más clara esta ampliación de deberes en el mundo de las políticas sanitarias integrales "respecto a la justicia, al respeto y a la creciente sensibilidad con relación a los principios de solidaridad y de subsidiariedad en el acceso a los medicamentos y las tecnologías disponibles..."62.

Dichos principios recuerdan las obligaciones de los especialistas ofrecer medios e instrumentos de técnicos de medida e interpretación y ofrecer pistas de solución de los problemas tras reflexiones complejas-; y las propias de cada ciudadano en ámbitos tan dispares como el control de gastos, el uso de recursos limitados, o el reciclaje de residuos.

Tras ampliar el colectivo de sujetos responsables y en el ejercicio de repensar lo humano sobre lo que se basarán las actuaciones legisladas

${ }^{60}$ JosÉ IGNACIO CALLEJA, Moral social cristiana: presupuestos y claves para un modelo crítico, en: Miguel Rubio - Vicente García - Vicente Gómez Mier (dirs.), La Ética cristiana hoy. Horizontes de sentido, Madrid 2003, 698.

${ }^{61}$ Cfr. Rocío Mendoza, Entrevista a Juan Carlos Izpisúa, en: Diario Montañés (2 de febrero de 2020).

https:/www.eldiariomontanes.es/sociedad/salud/entrevista-izpisua-envejecimiento20200202003330-ntrc.html (febrero del 2020)

${ }^{62}$ Zygmunt Zimowski, Prólogo, en: Pontificio Consejo Para los agentes SAnitarios (para la Pastoral de la Salud), Nueva Carta de los Agentes Sanitarios (Pastoral 101), Sal Terrae, Maliaño 2017, 10. 
crece la exigencia de compartir criterios con otros ámbitos que trabajan el justo actuar ${ }^{63}$.

Es un proceso paralelo al que desde la teología se pide tener los mismos criterios en el discernimiento de la moral social para la moral de la persona:

Durante décadas muchos teólogos moralistas hemos expresado el deseo y la reivindicación de que el abordaje aceptado oficialmente en la moral de la Iglesia en todo lo relacionado con lo social siguiendo la orientación marcada por el Concilio, se aplicase sistemáticamente al ámbito de la moral de la persona (sexual, matrimonial y bioético) ${ }^{64}$.

La reflexión que sostiene las políticas de la vida debe hacer el esfuerzo de unificar los criterios con la ética político/social para evitar hipocresías - popularmente denominado tener una doble vara de medir-y captar el significado profundo de la dignidad del ser humano, base de todos los derechos de un ser relacional, de una persona inmersa en un colectivo humano que lo define y en el que desea integrarse con plena ciudadanía.

La consecuencia primera es la denuncia de las contradicciones de lo que se ha definido como bio-ciudadanía, que hace una interpretación objetivadora de la persona, por un lado, en mal maridaje con la afirmación de su valor, su dignidad, y el rechazo de otros tipos de objetivación brutal señalados con vehemencia.

Además, la gestión de políticas institucionales amplias buscarán la participación depurada de instituciones de otra índole -también religiosas- presentes en las sociedades plurales que comparten la preocupación en el campo sanitario por "la importancia que tiene en los mismos servicios sociales a los enfermos, ... la (presencia) de los agentes sanitarios, que deben guiarse por una visión integralmente humana de la enfermedad y, por lo mismo, han de saber entablar una relación plenamente humana con el hombre enfermo y que sufre" 65 .

${ }^{63}$ Como los espacios cívicos, la organización de la ciudad o la estructura de lo que Marc Augé denominó los no lugares para pensarlos entre todos.

${ }^{64}$ Cfr. Julio Luis Martínez, Conciencia, discernimiento y verdad (BAC 242. Teología. Estudios y ensayos), Madrid 2019, 73.

${ }^{65}$ JuAn PABLO II, Motu proprio Dolentium hominum, Roma 11 de febrero de 1985, 2. Recuérdese que este motu propio es el origen de la Pontificia Comisión para la Pastoral de los agentes sanitarios. 


\subsection{En la violencia hacia los ciudadanos}

Se ha calificado la sociedad actual como una sociedad del desamparo $^{66}$. En ella, si ya tienen difícil acomodo las personas en tensión constante por el éxito y la realización personal, mayores impedimentos sufren aquellas que, maltratadas por la lotería de la vida, deben convivir con sus dependencias.

El esfuerzo empleado en calcular la justicia desde la base de la igualdad de oportunidades, perfeccionado con la realización de las capacidades, y culminado con la integración en la sociedad no tendrá grandes recorridos si no consigue forzar discriminaciones positivas hacia dichas personas dependientes. Lo cual se consigue sosteniendo la imposición coercitiva con el sustento nutricio generado por humanismos integrales, capaces de reconocer la dignidad del ser humano aun cuando sus condiciones externas parezcan ocultarla.

En caso contrario, el ciudadano se inhabilitará para pensar en el semejante como un tú que aparece en el horizonte de la vida y ofrecer una relación humanizadora ante su vulnerabilidad. En definitiva, una antropología incompleta basada exclusivamente en el deseo, en la sola voluntad, cerrada a la trascendencia de lo humano (más allá de lo fenomenológico alcanzando lo espiritual y religioso) incapacita para pensar la realidad del maltratado.

No habrá capacidad de respuesta a la pregunta genesiaca ¿dónde está tu hermano? porque no se han alcanzado las condiciones de asumir la identidad propia, y como consecuencia para cargar con la realidad de la que el otro forma parte. Esta pérdida de la propia esencia, que desenfoca el aprecio de la naturaleza del otro, resulta un problema de dimensiones considerables en sociedades con altos porcentajes de discapacidades y en proceso de cronificación debido al envejecimiento.

Por otro lado, una reflexión reducida ¿no es cimiento de las causas de la pobreza y de la incapacidad política para acabar con ella? Si no se valora a la persona y se fundamenta su dignidad con criterios multidisciplinares

http://www.vatican.va/content/john-paul-ii/es/motu proprio/documents/hf_jp-ii motuproprio 11021985 dolentium-hominum.html (diciembre del 2019)

${ }^{66}$ Cfr., Flávia Andrade Almeida, $O$ sujeito moderno e o mal-ser na sociedade do desamparo: Le Monde Diplomatique/Ed. Brasil (19 de diciembre del 2019)

https://diplomatique.org.br/o-sujeito-moderno-e-o-mal-ser-na-sociedade-do-desamparo/ (diciembre del 2019) 
integradores se inhabilita la consecución de un diagnóstico riguroso de las causas de su pobreza y del modo de salir de ella. Téngase en cuenta que algunos estudios han señalado que la pobreza no es solamente una cuestión económica denunciando los vínculos existentes entre la relación socioeconómica de la familia con el desarrollo de la persona, de su cerebro y de sus habilidades cognitivas, nexos impensables hasta hace pocos decenios.

El crecimiento económico sin inversión en desarrollo humano -nutrición adecuada, educación de calidad, salud, infraestructuras, ciencia, cultura- no es sostenible y no podrá conducirnos a un futuro con verdadera equidad social ${ }^{67}$.

\section{3.- En la reducción cosificadora de la persona}

La Organización para la Cooperación y el Desarrollo Económico (OCDE) publicó en 2009 un informe cuya temática central era la bioeconomía. Dicho informe interdisciplinar marcaba una agenda de trabajo hasta el año $2030^{68}$ y presentaba las posibilidades de desarrollo en lo relativo a los campos de la producción primaria, salud e industria. Hacía referencia a los conocimientos biotecnológicos para desarrollar nuevos procesos con vistas a producir una gama de productos biofarmacéuticos, vacunas recombinantes, nuevas variedades vegetales y animales. Esos conocimientos incluyen expresamente el dominio del ADN y del ARN, proteínas y enzimas a nivel molecular; formas de manipular células, tejidos, órganos u organismos enteros, y los recursos de la bioinformática para el análisis de genomas y proteínas ${ }^{69}$.

${ }^{67}$ FACUndo MANES - MATEO NiRo, El cerebro del futuro ¿Cambiará la vida moderna nuestra esencia? (Contextos), Paidós, Barcelona 2019, 275-277.

${ }^{68}$ Organization For Economic Co-Operation And Development, The Bioeconomy to 2030. Designing a policy agenda, 2009. Ha sido complementado con otro informe en el año 2018. Organization For Economic Co-Operation And Development, Meeting Policy Challenges for a Sustainable Bioeconomy, 2018.

https://www.oecd.org/futures/long-termtechnologicalsocietalchallenges/thebioeconomyto2030designingapolicyagenda.htm (diciembre del 2019)

${ }^{69}$ Organization For Economic Co-Operation And Development, The Bioeconomy to 2030. Designing a policy agenda, 2009, 22-23. Citando otro Informe del Ministerio de Investigación, Ciencia y Tecnología de Nueva Zelanda. 
Por la manera de presentar las temáticas en dicho informe, sin hacer distinción de entidades, se desprende una clara cosificación de lo humano tratado de modo semejante a los otros seres. Dicho desde un organismo tan importante como la OCDE viene a implicar que políticamente se buscan bases legales para que el cuerpo humano esté disponible para "el uso de otros seres humanos"70.

Desde el momento que -a partir de cadáveres- es posible obtener órganos, tejidos, elementos que pueden ser utilizados para la resucitación/reparación de otros individuos los cuerpos humanos se convierten en un mercado de repuestos. Su objetivación primera y su posterior mercantilización transforma a las personas en objetos susceptibles de comercialización e instrumentalización.

Por las técnicas surgidas tras el descubrimiento de las células madre se ha generado -en una segunda etapa- una cultura que se corresponde con una voluntad de "crear un sujeto humano viviente para la investigación" "71 de manera especial en virología.

Frente a esta bio-violencia manipuladora e instrumentalizadora se posicionan aquellos autores que piensan el respeto a la persona en su integralidad y denuncian este proceso de degradación, objetivación y mercantilización del cuerpo y sus partes. Sin instalarse en la denuncia profundizan esquemas para corregir los riesgos de compra/venta y reducción anti humanista en campos tan variados y conflictivos para la vida como pueden ser el de la identidad y el género, los trasplantes, la experimentación o el tráfico de seres humanos y la prostitución.

Otro tipo de bio-violencia puede estar dándose en relación con el fin de la vida de personas socialmente improductivas y paliativamente costosas presionados hacia opciones más baratas y más 'socialmente responsables'. Enfermos crónicos, terminales, personas improductivas serán objeto de esta violencia susceptible de ser realizada por la familia, el personal sanitario y la propia sociedad con legislaciones ahorradoras, como tal vez haya sucedido ya en la gestión de la pandemia del coronavirus.

${ }^{70}$ Cfr. CÉline LAfontaine, Le corps-marché. La marchandisation de la vie humaine à l'ère de la bioéconomie, Éditions du Seuil, Paris 2014. Edición digital.

${ }^{71}$ A partir de las células He La que desde 1952 entraron en un proceso de cultivo, estandarización y envío por todos los laboratorios del mundo. Cfr. HANNAH LANDECKER, Culturing life. How Cells Became Technologies, HUP, Cambridge 2007 126-139. 
En esa atmósfera, una reflexión humanista plenificante permite situar y tratar adecuadamente a la persona al final de su vida, en el tránsito de la muerte, momento final y definitivo de humanización necesitado de compasión y misericordia ${ }^{72}$ que reniega de la espera interesada de material humano para trasplante. Es opuesta a las promesas -imposibles de constatar y muy probablemente infundadas- que ofrece el transhumanismo. Excava una veta antropológica que no trata de huir de lo humano, del tiempo, del espacio, del cuerpo, de la historia, sino que hace el esfuerzo por integrarlo en los límites del todo biográfico.

\subsection{En el trato con los animales y la relación con la naturaleza}

Uno de los conflictos bioéticos más mediáticos ${ }^{73}$ es el relacionado con la consideración jurídico/ética de los animales, de modo particular el de los simios superiores, porción más elevada -no la única- de la conservación de la creación inevitablemente unida al trabajo por la justicia ecológica ${ }^{74}$.

Evidentemente está en juego la concepción de persona que subyace bajo tales definiciones -ser humano-animal-naturaleza-, porque la adjudicación de derechos está relacionada con el estatus moral de la entidad a la que nos refiramos en virtud de los criterios utilizados para definirlas en las diversas teorías existentes.

Algunas estrategias aceptan como criterio para determinar el estatus moral de entidades personales las habilidades metacognitivas: autoconciencia, racionalidad, uso del lenguaje; propiedades relacionales, tener un rol y ser reconocido, con una continuidad en el tiempo, aunque puedan estar ausentes en algún momento. Se atribuyen a los individuos de determinadas especies sin dejar de asumir "que el ser humano adulto normal

${ }^{72}$ Cfr. Leo Pessini, Exigências para uma bioética inclusiva, en: MARIA InÊS dE CASTRO Millen - Ronaldo Zacharias (orgs), O Imperativo Ético da Misericórdia, Aparecida 2016, 199-219.

${ }^{73}$ Véase la discusión entre Jesús Mosterín y Fernando Savater generada hace unos años por un artículo publicado por este último. FernANDo SAVATER, El alma de los brutos: Diario El País (14 de enero de 1986) 9-10.

https://elpais.com/diario/1986/01/14/opinion/506041206 850215.html (diciembre de 2019)

${ }^{74}$ Papa Francisco, Carta encíclica Laudato Si' sobre el cuidado de la casa común, Roma, 24 de mayo del 2015, 92. 
es persona y poseedor de estatus moral completo"75. Para los animales, la condición mínima para considerarlo sujeto moral es la capacidad psicológica de entablar relaciones intersubjetivas ${ }^{76}$.

Otros autores sostienen la plausibilidad del estatus moral por el dolor que las entidades afectadas puedan sentir. Al menos tener experiencias de placer y dolor por la capacidad de sentir consciente (Sintiencia) ofrece una solución intuitiva, tal vez ambigua al no expresar suficientemente la diferencia entre sentir placer/dolor y tener conciencia (experiencia consciente) y generar deseos.

La posición clásica es la antropocéntrica (aunque el papa Francisco hable de 'ecología integral' y utilice la expresión 'antropocentrismo' para denunciar los excesos de la visión centrada absolutamente en el hombre). Se privilegia al ser humano constituido en «el centro de las preocupaciones relacionadas con el desarrollo sostenible» ${ }^{77}$ en virtud de su capacidad dialógica completa desde la que se reconoce su dignidad que exige respeto.

Una visión integrada ayuda a establecer criterios aplicables, un mismo fin para todas las entidades recurriendo al principio de equidad y el de igual consideración ${ }^{78}$, incluso cuando se hayan perdido o no se haya adquirido totalmente sus condiciones relacionales. De ese modo se evita cerrar en falso las consideraciones, el riesgo del especismo antropológico y se camina en la dirección adecuada para determinar el estatus moral de modo éticamente acertado.

Huyendo de posiciones extremistas en conflictos ecológicos y del cuidado de la naturaleza no animal, una adecuada comprensión de la persona

${ }^{75}$ Bernardo Aguilera Dreyse, Estatus moral y concepto de persona, en: Bernardo Aguilera - Juan Alberto Lecaros - Erik Valdés (eds.), Ética animal: Fundamentos empíricos, teóricos y dimensión práctica (Cátedra de bioética 32), UPCO, Madrid 2019, 122.

${ }^{76}$ PAmela BARONe - ANTONi Gomilla Benejam, Interacción intersubjetiva y persona: ¿Son los chimpancés sujetos morales?, en: Bernardo Aguilera - JuAn Alberto LeCARos - ERIK VALDÉs (eds.), Ética animal: Fundamentos empíricos, teóricos y dimensión práctica (Cátedra de bioética 32), UPCO, Madrid 2019, 89-108.

${ }^{77}$ Principio Primero de la Declaración de Río sobre el medio ambiente y el desarrollo (14 junio 1992), recogido en: PAPA FRANCISCO, Carta encíclica Laudato Si' sobre el cuidado de la casa común, Roma, 24 de mayo del 2015, 167.

${ }^{78}$ Bernardo Aguilera Dreyse, Estatus moral y concepto de persona, en: BERNARdo Aguilera - Juan Alberto Lecaros - Erik VAldés (eds.), Ética animal: Fundamentos empíricos, teóricos y dimensión práctica (Cátedra de bioética 32), UPCO, Madrid 2019, 115. 
y sus responsabilidades denuncia los comportamientos inaceptables para el futuro, y presenta al mismo tiempo las exigencias que afectan al propio individuo interactuando correctamente con su entorno. Cuestión aparte será que las contradicciones de la vida humana dificulten su aceptación ${ }^{79}$.

\section{Conclusión}

Recordando las sugerencias de los textos iniciales se ha insistido en que el progreso de la condición humana pasa por una reflexión de la persona unificada, que incluya el abismo de sus deseos y la fortaleza de su inteligencia, asumiendo la presencia del otro -al superar una concepción de excesos individualistas y autónomos- con el que se procede a la realización de la plenitud humana.

La preocupación por el ser humano y el empeño por no poner entre paréntesis ninguna de sus dimensiones es una tarea de suma importancia por las repercusiones que arrastra y que tienen su especial campo de juego en los conflictos y dilemas que plantea la bioética contemporánea. Dicha reflexión debe afectar no solamente a la entidad profunda de lo que es la persona en sus caracterizaciones ontológica, ética o jurídica, sino que tiene que ser estimulada una estimativa moral que incluya las capacidades y las exigencias relacionales ampliando la libertad y la autonomía de cada ciudadano.

$\mathrm{Al}$ incluir lo emotivo en el debate y tomando parte en el proceso de discernimiento ético se inmuniza al ciudadano frente a la indiferencia ante el sufrimiento, confrontándole con la realidad, hinchando el fuelle transformador que busca la justicia y la reconciliación social de los más empobrecidos $^{80}$ indicador importante de la madurez democrática.

${ }^{79}$ Como se desprende del estudio de Alina Koschmieder - Lucie Brice-MansenCAL - SANDRA HOIBIAN, Environnement : les jeunes ont de fortes inquiétudes mais leurs comportements restent consuméristes: Credoc 308. Consommation et modes de vie (diciembre del 2019)

https://www.credoc.fr/publications/environnement-les-jeunes-ont-de-fortes-inquietudesmais-leurs-comportements-restent-consumeristes (diciembre del 2019)

${ }^{80}$ Cfr. Julio Luis Martínez, Conciencia, discernimiento y verdad (BAC 242. Teología. Estudios y ensayos), Madrid 2019, 168-169. 
Las primeras víctimas de deficientes elaboraciones antropológicas son aquellas que tienen dificultades en seguir el ritmo integrador de la mayoría, impedidas por sus discapacidades o su menor capacitación. La deshumanización la pagan primeramente los más débiles, los menos inteligentes, los más enfermos, los más ancianos, los más pobres. Incorporarlos como objetos y sujetos de participación será el espacio privilegiado de una reflexión motivadora y de una hermenéutica de la persona atenta a las dependencias e incertidumbres de la gran familia humana necesitada de fraternidad ${ }^{81}$.

Una antropología integral necesariamente deberá ser una antropología exigente apoyada en el empeño multidisciplinar por comprender la condición humana en evolución conflictuada personal -pasiones versus razones- e institucionalmente.

Se ha sugerido que, en el ahínco científico, el aporte de la apertura a la Trascendencia -empeñada en racionalizar y hacer inteligibles y dialogables sus códigos particulares- puede ser muy válido tanto en el ámbito metafísico como en el de la toma de decisiones ${ }^{82}$. Mantener la dimensión mistérica de la persona, cuya comprensión necesita -pero escapa- a la suma articulada de todas las ciencias estimula la investigación continua, sostiene una amplitud que se sobrepone a la reducción experimental y técnica y ofrece una comprensión de la vida como un don, como algo que es dado, complementando visiones no religiosas de dicha donación ${ }^{83}$.

En relación con los dilemas bioéticos, las malas antropologías acaban siendo excluyentes en los debates políticos provocando daños colaterales y víctimas marginalizadas.

El gran y encomiable desarrollo que han adquirido las técnicas biomédicas generando unas ventajas irrenunciables, debe luchar contra la objetivación, instrumentalización y comercialización de la estructura

${ }^{81}$ Cfr. Papa Francisco - Gran Imán de Al-Azhar Ahmad Al-Tayyeb, Documento sobre la Fraternidad humana por la paz mundial y la convivencia común, Abu Dabi, 4 de febrero de 2019

http://w2.vatican.va/content/francesco/es/events/event.dir.html/content/vaticanevents/es/2019/2/4/fratellanza-umana.html (febrero del 2019)

${ }^{82}$ Cfr. J. Filipe Monteiro, Testamento vital. Nos dilemas éticos do fim da vida (Nãoficção- sociedade), Guerra e paz, Lisboa 2020,117-118.

${ }^{83}$ Cfr. Michael SAndel, Contra la perfección, Barcelona 2007, 146. 
corporal humana, caldo de cultivo de nuevas formas de injusticia y bioviolencia.

La acentuada preocupación por la ecología y el desarrollo sostenible -dentro de la cual se ha situado la dignidad de los animales-, precisa también de unos criterios bien enfocados para identificar sin confusiones el corazón de las cuestiones planteadas y encontrar soluciones que no desprecien lo propio del ser humano ${ }^{84}$, ni disminuyan lo específico de los animales, las plantas o el medioambiente en general. También se ha sugerido que el desarrollo de la neurociencia, y en particular de la neuroética, estimule esta labor de repensar la conciencia de ser humano desde su interior.

${ }^{84} \mathrm{Si}$ al fin y al cabo el ser humano es un simio mejorado, no resulta fácil identificar los límites que le separan de los bonobos que al parecer tienen la costumbre de besarse para aliviar tensiones en la manada. FRANS DE WAAL, El mono que llevamos dentro, Tusquets, Barcelona 2007, 151; ID., El bonobo y los diez mandamientos. En busca de la ética entre los primates (Boonet ciencia 70), Barcelona 2014. 